
COLOMBIA: ANÁLISIS

\title{
DE LA SENTENCIA
} C-083/1995 DE LA CORTE CONSTITUCIONAL DE COLOMBIA

Daniel Fernando Gómez Tamayo

Universidad Cooperativa de Colombia

El presente documento de trabajo ha sido incluido dentro de nuestro repositorio institucional como Apropiación social de conocimiento por solicitud del autor, con fines informativos, educativos o académicos. Asimismo, los argumentos, datos y análisis incluidos en el texto son responsabilidad absoluta del autor y no representan la opinión del Fondo Editorial o de la Universidad.

\section{DISCLAIMER}

This coursework paper has been uploaded to our institutional repository as Social Appropriation of Knowledge due to the request of the author. This document should be used for informational, educational or academic purposes only. Arguments, data and analysis included in this document represent authors' opinion not the Press or the University. 


\section{ACERCA DEL AUTOR}

Daniel Fernando Gómez Tamayo, magíster y doctor en Derecho Canónico de la Pontificia Universidad Javeriana. Coordinador del Área de Humanidades, Facultad de Derecho, Universidad Cooperativa de Colombia, sede Bogotá.

Correo-e: daniel.gomezt@campusucc.edu.co

\section{CóMO CITAR ESTE DOCUMENTO}

Gómez-Tamayo, D. F. (2020). Las fuentes del derecho en Colombia: análisis de la Sentencia C-083/1995 de la Corte Constitucional de Colombia (Generación de contenidos impresos N. 18). Bogotá: Ediciones Universidad Cooperativa de Colombia. doi: https://doi. org/10.16925/gclc.12

Este documento puede ser consultado, descargado o reproducido desde nuestro repositorio institucional (http://repository.ucc.edu.co/ handle/20.500.12494/7369) para uso de sus contenidos, bajo la licencia de Creative Commons Reconocimiento-NoComercial-SinObraDerivada 4.0 Internacional. http://creativecommons.org/licenses/by-ncnd/4.0/ 


\title{
18 LAS FUENTES DEL DERECHO EN COLOMBIA: ANÁLISIS DE LA SENTENCIA C-083/1995 DE LA CORTE CONSTITUCIONAL DE COLOMBIA
}

\author{
Daniel Fernando Gómez Tamayo
}

\section{Resumen}

El objetivo principal de esta investigación es ofrecer una propuesta hermenéutica que permita armonizar las fuentes jurídicas nacionales con las fuentes jurídicas internacionales, determinar el uso adecuado de los métodos de interpretación y establecer un sistema técnico de la valoración de las pruebas. Ciertamente, con la entrada en vigencia de la Constitución Política de 1991 cambió el panorama de las fuentes jurídicas que regía en Colombia, y en la actualidad tenemos un modelo mixto de fuentes del derecho; en efecto, los constituyentes de 1991 importaron figuras jurídicas que provienen del common law que están mezcladas con las fuentes del modelo romano germánico que tenía nuestro país antes de 1991. ¿Puede una sentencia que produce efectos jurídicos interpartes ser considerada como precedente? Personalmente, tengo mis dudas razonables. En conclusión, ¿cuándo una sentencia constituye precedente? Primero, cuando produce efectos erga omnes y no produce efectos interpartes, cuando es proferida por una Corte de cierre, cuando una sentencia tiene pruebas sustentadas en medios de pruebas y cuando no ha sido declarado nula, pues lo cierto es que el artículo 49 en su inciso 2 del Decreto 2067 de 1991 permite la nulidad de las sentencias de la Corte Constitucional por violación del debido proceso. Fi-nalmente, es importante dejar en claro que la Corte Cons-titucional de Colombia no tiene competencia para co-nocer sobre la exequibilidad de tratados internacionales anteriores a la Constitución Política de 1991, porque estos tratados internacionales se rigen por el principio pacta sunt servada y son válidos según la Convención de Viena y la regla de reconocimiento vigente a la celebración. Es decir que la Corte Constitucional solamente puede conocer sobre los tratados internacionales que se celebren a partir de 1991.

Palabras clave: doctrina, equidad, jurisprudencia, ley, tratados internacionales. 


\section{TABLA DE CONTENIDO}

I. INTRODUCCIÓN

II. Fuentes jurídicas en la Constitución Política de 1991

III. Criterios AUXiliares DE LA ACtividAd JUdicial 5

3.1 La equidad 5

3.2 La jurisprudencia 6

3.3 Los principios generales del derecho 9

3.4 Doctrina 9

IV. LAS FUENTES SUBSidiarias (Ley 153 DE 1887) 10

4.1 Analogía 10

4.2 Las reglas del derecho $\quad 10$

4.3 La costumbre $\quad 11$

4.4 Los principios de derecho natural 11

V. El activismo judicial, el debate en la Corte Constitucional 11 de Colombia: ¿LOS Jueces son discrecionales?

VI. TÉCNICA DE HERMENEÚTICA CONSTITUCIONAL: EL TEST

DE IGUALDAD Y LA INTERSECCIÓN ENTRE DERECHOS Y LIBERTADES

$\begin{array}{ll}\text { VII. EL PRECEDENTE Y EL VALOR VINCULANTE } & 14\end{array}$

VIII. Conflicto EntRe Un TRATAdo Internacional y 14

la Constitución Política

$\begin{array}{ll}\text { IX. Conclusiones } & 16\end{array}$

$\begin{array}{ll}\text { REFERENCIAS } & 17\end{array}$ 


\section{INTRODUCCIÓN}

Ciertamente, con la entrada en vigencia de la Constitución Política de 1991 cambió el panorama de las fuentes jurídicas formales que regían en Colombia, y en la actualidad tenemos un modelo mixto de fuentes del derecho; en efecto, los constituyentes de 1991 importaron figuras jurídicas que provienen del common law que están mezcladas con las fuentes del modelo romano germánico que tenía nuestro país antes de 1991.

Lo cierto es que la Corte Constitucional colombiana antes era una simple Sala de la Corte Suprema de Justicia con el mismo rango jerárquico que las otras cortes de cierre; no obstante y por problemas hermenéuticos de los jueces constitucionales de Colombia, la Corte Constitucional se convirtió en una supercorte aparentemente con poderes omnímodos, desconociendo que el único rol que tiene la Corte Constitucional de Colombia es el de crear reglas de interpretación cuando existe intersección de derechos y libertades, o el de incidir en las políticas públicas legislativas con el activismo judicial. Sin embargo, es claro que los jueces constitucionales no tienen poder constituyente y tampoco detentan la potestad para colegislar, pues la Constitución Política únicamente se puede reformar por la voluntad mayoritaria del constituyente primario o por medio de un acto legislativo según los requisitos establecidos.

Con estas reflexiones, pretendo ofrecer una propuesta hermenéutica que permita armonizar las fuentes jurídicas nacionales con el orden jurídico internacional; igualmente, me propongo determinar el uso adecuado de los métodos de interpretación y establecer un sistema técnico de la valoración de los medios de prueba, las pruebas y las evidencias.

\section{Fuentes JURÍDicAs en LA Constitución Política de 1991}

El artículo 230 de la Constitución Política de 1991 establece que los jueces en sus providencias solamente están sometidos al imperio de la ley, puesto que esta es la única fuente formal del derecho en Colombia; no obstante, ¿qué sucede cuando la ley no es clara?, o ¿qué sucede cuando la norma jurídica tiene vacíos o cuando existen contradicciones normativas?

Prima facie, resulta claro que en estos casos el juez no está sometido al imperio textual de la ley, ello quiere decir que la ley solamente es aplicable al caso concreto cuando el texto de la ley sea claro, esto es, cuando el significado de las palabras y el lenguaje sea correcto, cuando la norma jurídica no tenga vacíos o cuando la ley no entre en contradicción con otras leyes; pero cuando la ley o la norma jurídica tiene vacíos o contradicciones, el juez debe acudir a los criterios auxiliares previstos en el artículo 230 de la Carta Magna o, en su defecto, a las fuentes subsidiarias previstas en la Ley 153 de 1887.

\section{CRiterios AUXiliares DE LA ACTIVIDAD JUDICIAL}

Los criterios auxiliares de la actividad judicial son: la equidad, la jurisprudencia, los principios generales del derecho, y la doctrina.

\subsection{LA EQUIDAD}

Es un criterio auxiliar de la actividad judicial que proviene del common law, en virtud del cual los jueces constitucionales en su discrecionalidad pueden crear reglas jurídicas de interpretación 
en la parte motiva de las sentencias, y que sirven para argumentar y resolver casos similares de tutela o de laudos arbitrales según lo establece el artículo 116 de la Constitución Política de 1991 y la Ley 1563 de 2012. Finalmente, es importante dejar en claro que la equidad no se puede confundir con la analogía, que es una fuente subsidiaria prevista en la Ley 153 de 1887 y que consiste en la aplicación de un raciocinio legal a un caso similar cuando no existe norma expresa aplicable.

\subsection{LA JURISPRUDENCIA}

Con respecto a la jurisprudencia, vamos a revisar, en primer lugar, las sentencias de jueces extranjeros y, posteriormente, las sentencias de jueces nacionales según la competencia y jurisdicción.

\section{Sentencias extranjeras}

Las sentencias que profieren la Corte Penal Internacional y la Corte Interamericana de Derechos Humanos son precedentes en nuestro ordenamiento jurídico por virtud del principio del bloque de constitucionalidad (artículos 93 y 94 de la Constitución Política de 1991), pues resulta un contrasentido que los tratados de derechos humanos y de derecho internacional humanitario que fueron celebrados por Colombia antes de 1991 sean sometidos a revisión por la Corte Constitucional de Colombia dado que no tiene competencia en virtud del principio de legalidad; además, ya están perfeccionados según la Convención de Viena sobre Celebración de los Tratados Internacionales y la regla de reconocimiento preexistente al acto se imputa. Por ende, estos tratados rigen en el ordenamiento jurídico interno en virtud del principio pacta sunt servanda (Organización de las Naciones Unidas [ONU], 1996, artículo 26).

Otro aspecto muy distinto es el control de convencionalidad, que pretende revisar que las reglas, los precedentes y los estándares de la Corte Interamericana de Derechos humanos, la Convención Americana de Derechos Humanos, la Convención Interamericana para Prevenir y Sancionar la Tortura, la Convención Interamericana sobre Desaparición Forzada de Personas, la Convención Interamericana para Prevenir, Sancionar y Erradicar la Violencia contra la Mujer y la Convención de Belem do Pará, sean cumplidos por parte de los Estados en el ordenamiento jurídico interno (Quinché, 2017). Esto es lo que la jurisprudencia internacional denomina como el bloque de convencionalidad, es decir, las reglas, los precedentes y los estándares que imponen las Cortes Interamericanas de Derechos Humanos y que hacen alusión específicamente a estos tratados internacionales.

En el caso de las sentencias del Tribunal Europeo de Derecho Humanos, del Tribunal de Justicia de la Unión Europea y de la Corte Suprema de Estados Unidos, es claro que no son vinculantes en Colombia por razón del principio de competencia y jurisdicción, es decir, en virtud de la territorialidad de la ley, en razón de los sujetos y en razón de la materia. Por consiguiente, estas sentencias extranjeras tienen que surtir el trámite previo de exequátur, o de homologación, para ser consideradas como un criterio auxiliar de la actividad judicial en Colombia (Camacho, 2004, pp. 252255).

Este mecanismo se debería aplicar en la jurisdicción constitucional para determinar si las fuentes jurídicas extranjeras están conformes con las normas constitucionales y, por ende, pueden ser consideradas como criterios auxiliares de la actividad judicial, pues en muchas sentencias de la Corte Constitucional de Colombia los jueces citan sentencias de Cortes extranjeras que no son fuentes del derecho en Colombia, aunque sean fuentes del argumento. En este sentido, Hernán Fabio López Blanco (2009, p. 859), honorable magistrado de la Corte Suprema de Justicia, sostiene que 
"la sentencia extranjera será válida siempre que no se oponga al conjunto de condiciones fundamentales de la vida social instituidas en una comunidad jurídica, y siempre que en el otro Estado se reconozca igual fuerza a las decisiones judiciales proferidas por jueces nacionales".

\section{Sentencias nacionales}

\section{Corte Constitucional de Colombia}

Las sentencias de la Corte Constitucional colombiana (Tipo C) son aquellas providencias que resultan del control (abstracto) o del examen de constitucionalidad por la Sala en pleno de leyes de inferior jerarquía a la regla de reconocimiento de 1991. En nuestra opinión, y según el artículo 243 de la Constitución Política de 1991 y el artículo 48 inciso 1 de la Ley 270 de 1996, las sentencias de control de constitucionalidad son precedente porque los jueces constitucionales pueden estudiar la casuística que tiene relación directa con la ley que está bajo examen del control de constitucionalidad, y siempre que tengan pruebas interdisciplinarias o evidencias forenses, pues en este caso las sentencias producen efectos erga omnes y su desconocimiento genera prevaricato según lo expresó la Corte Constitucional colombiana en la Sentencia C -355 de 2008. El precedente única y exclusivamente puede ser definido por las altas cortes que administran justicia, con el fin de dar seguridad jurídica en la técnica hermenéutica del sistema normativo jurídico existente, aunque para otros constitucionalistas las sentencias que se profieren en virtud del control abstracto no generan precedente (López, 2006, pp. 50-57).

Las sentencias de unificación de jurisprudencia (Tipo SU) tienen, como su nombre lo indica, la función de unificar la ratio decidendi que produce la Corte Constitucional en un tiempo determinado con respecto a un tópico; estas sentencias solo nos muestran un mapa de la línea jurisprudencial y argumentativa que han tenido los magistrados mayoritarios y contramayoritarios para observar los vacíos y los problemas jurídicos sustanciales y procesales que faltan por resolver y los que ya se han resuelto; también estas sentencias pueden producir efectos para terceros y son proferidas por la Sala en pleno. Las sentencias de tutela (Tipo T) son aquellas que resuelven los casos concretos de protección de los derechos fundamentales y libertades civiles; estas sentencias pueden servir como argumento para fundamentar un caso similar de tutela que se va a incoar ante el juez, pero todo depende de la claridad de los hechos, de las circunstancias y de las pruebas, pues no pueden existir precedentes transitorios según el artículo 48 inciso 2 de la Ley 270 de 1996.

Las sentencias de tutela producen efectos jurídicos interpartes, y cuando se utilizan las razones judiciales o los argumentos del holding para sustentar otro caso de tutela, hablamos de equidad y no de analogía. En resumidas cuentas: una sentencia de control de constitucionalidad que produce efectos erga omnes no puede ser modificada por una sentencia de tutela que produce efectos interpartes; no obstante, las sentencias de tutela sí tienen que observar la ratio decidendi y el precedente de las sentencias de control de constitucionalidad Tipo C.

Finalmente, en nuestra opinión existen sentencias de la Corte Constitucional Tipo T, SU y C que no tienen los medios de prueba conducentes, razonables e indispensables para tomar una decisión judicial según lo exige el Decreto 2067 de 1991 y el Decreto 2591 de 1991. En tanto en cuanto en unos casos toma la decisión judicial simplemente con la actuación administrativa, en otros casos pareciera que la Corte Constitucional tomara una decisión política y no practicaran nuevos medios de prueba teniendo la obligación de hacerlo. 
Hoy por hoy, la Ley 1564 de 2012, es decir, en el artículo 1 del Código General del Proceso se establece que este se aplica a todos los asuntos de cualquier jurisdicción o especialidad cuando ejerzan funciones jurisdiccionales. V. gr., en la Sentencia T-406 de 1992 se define el Estado social de derecho alemán, que es una economía desarrollada; sin embargo, no existe el concepto técnico de los expertos en la ciencia económica.

En la Sentencia C-221 de 1994, sobre despenalización de la dosis personal, no existen conceptos técnicos de toxicólogos o de forenses. En la Sentencia SU-47 de 1999, sobre la inviolabilidad parlamentaria, no existen declaraciones, ni confesiones, ni interrogatorios, ni testimonios o pruebas documentales, indicios o pruebas técnicas de audio o de las cámaras de las sesiones del Congreso de la República.

\section{Corte Suprema de Justicia}

Si se trata de una sentencia de casación (penal, laboral o civil) que tiene evidencia científica, pruebas interdisciplinarias o argumentos técnicos en la parte motiva, entonces esta sentencia de casación tiene el valor de precedente vinculante para otros casos. A contrario sensu, si la sentencia no cumple con los presupuestos probatorios anteriores, entonces en este caso habrá que reunir tres decisiones de la Corte Suprema de Justicia con respecto a un mismo tópico, pero el valor probatorio será tan solo de doctrina probable porque son obiter dictum, es decir, que no será precedente vinculante para ningún juez (artículo 10 de la Ley 153 de 1887).

\section{Exequátur de sentencias}

Según la interpretación de los artículos 605, 606, 607 y 608 de la Ley 1564 de 2012 (Código General del Proceso):

La Corte Suprema de Justicia corre traslado al Ministerio público para que la delegada de asuntos civiles emita el concepto de oposición o no al exequátur, acto seguido solicita al Ministerio de Relaciones Exteriores para que certifique si existe tratado internacional o convenio vigente de reconocimiento recíproco de sentencias pronunciadas por autoridades jurisdiccionales de ambos países, y posteriormente la Corte Suprema de Justicia verifica tanto los requisitos de forma v. gr: debida autenticación, traducción, legalización y ejecutoria; como los requisitos de fondo: contenido de la determinación, medidas que no pueden contradecir disposiciones de orden público interno, ni asuntos que comprometan derechos reales sobre bienes que se hallen en el país, ni extender a conflictos de competencia exclusiva de las autoridades colombianas, como tampoco aquellos asuntos sometidos que se hallen en trámite o con sentencia en firme. (Corte Suprema de Justicia, 2016, Expediente SC 16787)

Finalmente, es importante tener en cuenta que en el caso de laudos arbitrales proferidos por tribunales internacionales o en el extranjero, estos deben ser reconocidos por la Corte Suprema de Justicia según la Convención de Nueva York de 1958 y la Ley 1563 de 2012 (Estatuto Arbitral Nacional e Internacional).

\section{Consejo de Estado}

En las sentencias del Consejo de Estado, se aplican los mismos criterios de las sentencias de la Corte Suprema de Justicia para efectos de valoración y tasación probatoria; esto es, una sentencia será precedente si tiene argumentos interdisciplinarios, evidencia forense $\mathrm{y}$ pruebas técnicas como por ejemplo la sentencia que condena a la Nación, al MinGobierno, al MinDefensa, al MinJusticia, a la Policía Nacional, al DAS y al Fondo Rotatorio del Ministerio de Justicia por falla del servicio en la toma del Palacio de Justicia (Consejo 
de Estado, Sección III, 1994, Expediente 9276); o las sentencias que conoce el plenario del Consejo de Estado que declaran la nulidad de decretos generales por inconstitucionalidad pueden ser precedente porque producen efectos jurídicos erga omnes (artículo 237 de la Constitución Política de Colombia, artículo 49 de la Ley 270 de 1996 y artículo 135 de la Ley 1437 de 2011 CPAC). De lo contrario, habrá que reunir tres decisiones con respecto a un mismo tópico y esos argumentos constituyen valor de doctrina probable, porque son obiter dictum y no ratio decidendi.

\subsection{LOS PRINCIPIOS GENERALES DEL DERECHO}

Son los fundamentos sobre los cuales se estructura una democracia civilizada y el Estado social de derecho, v. gr.: el respeto a la dignidad humana (artículo 1 de la Constitución Política), la prelación de la norma constitucional (artículo 4), la soberanía popular, la responsabilidad jurídica de los particulares y de los funcionarios públicos (artículo 6), el debido proceso y la presunción de inocencia (artículo 29), y la buena fe (artículo 83). De suerte que existen unos principios generales del derecho tales como: la buena fe, el enriquecimiento sin justa causa y el de legalidad, que están reconocidos expresamente o implícitamente en la Constitución Política de 1991.

No obstante, existen otros principios generales del derecho que no están expresamente reconocidos en la regla de reconocimiento de H.L.A. Hart, tal es el caso del error común de derecho. Un caso práctico y concreto de este principio se presenta cuando los servidores públicos y los abogados utilizan los argumentos sustanciales y persuasivos de las sentencias de la Corte Constitucional, aunque procesalmente las sentencias Tipo T, SU y C no tengan los medios de prueba conducentes, indispensables y razonables, ya que únicamente cuando se trata de hechos notorios o cuando el juez llegue al convencimiento de la situación litigiosa puede dejar de practicar las pruebas solicitadas.

\subsection{DOCTRINA}

La doctrina no es la opinio iuris como lo pensaban los grandes juristas con mentalidad romano-germánica; en todo caso, si lo importante en el litigio jurídico son los medios de prueba y las pruebas, entonces por doctrina se entienden hoy por hoy los argumentos técnicos, las evidencias forenses o de laboratorios, y las pruebas interdisciplinarias que provienen de otras disciplinas del conocimiento, v. gr.: las pruebas periciales, las evidencias de toxicología y balística, los test psicológicos, los exámenes de laboratorio y el procedimiento quirúrgico (Sentencia C-086 de 2016). Igualmente, hace parte de la doctrina el concepto técnico de la economía, los antecedentes históricos, las investigaciones de campo de la sociología y la doctrina constitucional (artículo 8 de la Ley 153 de 1887).

Las sentencias de la Corte Suprema de Justicia o del Consejo de Estado que no tengan una ratio decidendi sustentada en pruebas técnicas o en evidencias forenses sobre un mismo tópico, o que sean obiter dictum, adquieren el valor de doctrina probable. En conclusión, desde la epistemología jurídica no se puede confundir la opinión con un concepto o con un dictamen. La Corte Constitucional establece en su jurisprudencia (Sentencia C-621 de 2015) que los jueces deben justificar claramente las razones jurídicas y probatorias por las cuales se apartan de la doctrina probable de la Corte Suprema de Justicia y del Consejo de Estado en casos similares, como se infiere de una interpretación sistemática del artículo 7 del Código General del Proceso (Ley 1564 del 2012). 


\section{LAS FUENTES SUBSIDIARIAS (LEY 153 DE 1887)}

Con respecto a las fuentes subsidiarias, tenemos que advertir que cuando el juez encuentra vacíos, contradicciones normativas o problemas del lenguaje, puede acudir a otras técnicas contempladas en la Ley 153 de 1887, como la analogía, las reglas del derecho, la costumbre y los principios de derecho natural.

\subsection{ANALOGÍA}

Desde la ciencia jurídica, la analogía es un razonamiento legal que se aplica a un caso similar cuando no existe una norma jurídica expresa y concreta aplicable al supuesto fáctico concreto; la analogía se puede usar por ejemplo en asuntos civiles, comerciales y en algunos asuntos procesales según el artículo 1 del Código General del Proceso (Ley 1564 de 2012), pero nunca se puede aplicar en casos penales porque la interpretación de la conducta ilícita es naturaleza exegética, al igual que la interpretación de las nulidades procesales.

En resumidas cuentas, la analogía no se debe confundir con la equidad, por ello en la Ley 153 de 1887 se establece en el artículo 8: "Cuando no haya ley exactamente aplicable al caso controvertido, se aplicarán las leyes que regulan casos o materias semejantes, y en su defecto, la doctrina constitucional y las reglas generales de derecho".

Un ejemplo claro de analogía lo establece el artículo 822 del Código de Comercio, que dice: "Los principios que gobiernan la formación de los actos y contratos y las obligaciones de derecho civil, sus efectos, interpretación, modo de extinguirse, anularse o rescindirse, serán aplicables a las obligaciones y negocios jurídicos mercantiles, a menos que la ley establezca otra cosa".
Por ejemplo, la Corte Suprema de Justicia ha establecido: "A falta de derecho convencional, se acogen las normas de la respectiva ley extranjera para darle a la sentencia la misma fuerza concedida por esa ley a las proferidas en Colombia" (Corte Suprema de Justicia, 2014, Expediente SC 6143).

\subsection{LAS REGLAS DEL DERECHO}

Las regulae iuris, o reglas de hermenéutica judicial, son axiomas de sabiduría judicial producto del razonamiento lógico de los jueces (pretores) y de la experiencia profesional, es decir, del análisis argumentativo de la evidencia y la experiencia en la sana crítica de los medios de prueba que resulta del legítimo contradictorio. El juez ha establecido unas reglas hermenéuticas útiles para resolver conflictos de las leyes en el tiempo y en el espacio, o para dar solución a casos de intersección entre derechos y libertades constitucionales; v. gr.: la norma superior prevalece sobre la inferior, la norma especial se prefiere a la general, la norma posterior prevalece a la anterior, el que puede lo más también puede lo menos, el derecho sustancial prevalece sobre el formal, en caso de conflicto los derechos de los niños prevalecen sobre los derechos de los demás.

Existen reglas del derecho de rango constitucional; v. gr.: los derechos de los niños prevalecen sobre los derechos de los demás (artículo 43 de la Constitución Política de 1991), o la regula iuris que dice: el derecho sustancial prevalece sobre el derecho formal (artículo 228 de la Constitución Política de 1991). Según expertos en diplomacia y derecho internacional humanitario, también existen reglas del derecho que provienen de la sociología jurídica y que son útiles en un país que tiene un conflicto armado interno, v. gr.: "unas son las leyes en la zona urbana, y otras muy distintas son las leyes en la zona rural donde existe presencia del conflicto armado". 


\subsection{LA COSTUMBRE}

Igualmente, tenemos las costumbres praeter legem y secundum legem como fuentes subsidiarias según la Ley 153 de 1887, y en efecto, la costumbre no es un criterio auxiliar de la actividad judicial, pero sí es una fuente subsidiaria. La costumbre contra-legem jamás constituye fuente de la ciencia jurídica, y en ningún caso se puede usar como técnica válida de argumentación o para resolver problemas jurídicos de interpretación de leyes confusas, ambiguas o con lagunas. Por ejemplo: ¿será válido probatoriamente presentar estadísticas de lugares clandestinos donde se practica el aborto en un proceso en la Corte Constitucional?, ¿puede una costumbre contra-legem ser fuente del derecho? Un ejemplo típico de costumbre legal que no es origen religioso es el derecho de todo niño a tener una madre y un padre.

La costumbre general para que sea fuente subsidiaria debe estar conforme con la Constitución Política y la ley, y además tener un referente objetivo ético de aspiración en una democracia incluyente y participativa, como lo planteó Lon Fuller en su obra La moral del derecho. La pregunta es: ¿cuál moral?, pues los argumentos religiosos en debates de políticas públicas en la Corte Constitucional son discutibles y cuestionables (artículo 13 de la Ley 153 de 1887). Finalmente, y con respecto a los requisitos de la prueba de la costumbre mercantil, se pueden estudiar los artículos 178 y 179 del Código General del Proceso (Ley 1564 de 2012).

\subsection{LOS PRINCIPIOS DE DERECHO NATURAL}

El ordenamiento jurídico romano se fundamentó en tres principios que son: dar a cada uno lo justo, vivir honestamente y no hacer daño a nadie (D'Ors, 1968). Los principios de derecho natural, según el exmagistrado fallecido Carlos Gaviria Díaz, son extrasistemáticos (artículo 13 de la Ley 153 de 1887). Son una fuente subsidiaria de la ciencia jurídica, y se refiere a los parámetros razonables que respetan la dignidad de la persona humana, los derechos fundamentales y la salud integral del ser humano.

Existen muchos principios del derecho natural que se pueden inferir de los tratados internacionales de derechos humanos y de derecho internacional humanitario, v. gr.: los protocolos I y il de Ginebra o los aportes de la ciencia médica y de la sana antropología. V. gr. según la Sentencia T-395/15: "Se justifica una cirugía de bypass gástrico por motivos de salud cardiovascular pero no por simples motivos estéticos". Otro ejemplo es la legítima defensa, siempre cuando esta sea proporcional a la acción inicial injusta.

\section{El ACTIVISMO JUdiCIAL, EL DEBATE EN LA CORTE Constitucional DE Colombia: ¿ LOS JUECES SON DISCRECIONALES?}

Ronald Dworkin (1978, p. 81) sostiene que los magistrados de la Corte Constitucional pueden crear reglas de interpretación constitucional o, lo que en el método sistemático se llama la técnica de las interpolaciones que estén conformes con los tratados internacionales, con los precedentes, con las normas constitucionales, con los principios y los valores constitucionales.

No obstante, los jueces constitucionales no pueden colegislar y tampoco pueden modificar los textos constitucionales y hacerle decir a la Carta Magna lo que el texto constitucional no dice, pues la Corte Constitucional colombiana no detenta el poder constituyente. Cuando hay casos difíciles, el juez constitucional lo único que puede hacer es crear reglas de interpretación constitucional para garantizar 
la eficacia normativa, en tanto en cuanto el juez constitucional en este caso no puede utilizar el método exegético. Sin embargo, para Hart (1961, pp. 155-200 los jueces son absolutamente discrecionales al resolver un caso: "Hoy, con la nueva Constitución, los derechos son en términos de H. L. Hart aquello que los jueces dicen a través de las sentencias de tutela, dado que la interpretación de los derechos humanos es de textura abierta".

Según Hart (1981), el sistema jurídico puede ser incompleto, pues existen normas jurídicas que tienen vacíos y ambigüedades en el significado del lenguaje, y por ello se puede identificar en las normas una zona de penumbra y otra zona de claridad. La primera se presenta cuando el significado de las palabras resulta ser equívoco y ambiguo en el texto normativo, pero el juez en estos casos no puede aplicar la norma de manera clara al supuesto fáctico concreto mientras exista discusión y duda razonable en la interpretación correcta de la norma que presenta la laguna. Por el contrario, la segunda zona se da en el caso de que el significado de las palabras del texto normativo sea unívoco y la solución se encuentre preestablecida de manera clara por la autoridad que configuró la norma, de suerte que en este caso el juez no tiene ninguna duda y dificultad para aplicar la norma al supuesto fáctico concreto.

¿Por qué razón el lenguaje de las leyes no es claro?, ¿por qué razón las normas jurídicas tienen vacíos y contradicciones?, ¿por qué razón la ley que reglamenta el funcionamiento del congreso no prevé una técnica legislativa para hacer las leyes comunes, marco, estatutarias, orgánicas o un acto legislativo? ¿Por qué razón los congresistas hacen leyes que pueden ser inexequibles si se presume que deben conocer la Constitución Política? Ronald Dworkin, por su parte, denominó a la zona de penumbra de Hart como un caso difícil, dado que en principio pareciera que se admitieran muchas respuestas en la interpretación de una laguna del texto normativo. Mientras que a la zona de claridad la denominó un caso fácil, porque para ese problema la respuesta interpretativa es única y correcta. De otro lado, y cuando se trata de un caso difícil, según Dworkin, al juez le correspondía la difícil tarea de crear o de inferir una regla judicial correcta dentro de los límites impuestos por el precedente judicial, los principios políticos de la regla de reconocimiento y la costumbre de la sociedad generalmente aceptada (Dworkin, 1978, p. 81).

Es decir, cuando el juez no encuentra ley aplicable al caso, le corresponde, por medio de un proceso cetético (investigativo), inferir una regla lógica con el sistema jurídico para salir de la laguna respectiva, siempre y cuando no exista en un caso similar un precedente judicial, stare decisis, que tenga fuerza vinculante sobre la nueva decisión, pues de lo contrario el precedente judicial sería el punto de Arquímedes y de referencia para la argumentación y solución de la nueva decisión judicial. De lo anterior se infiere que para Dworkin su capacidad discrecional está limitada por el precedente y los principios políticos, v. gr.: la equidad y la igualdad, ya que al juez le corresponde justificar su decisión con argumentos fuertes y persuasivos de acuerdo con los principios y los valores determinados por el precedente.

No se puede olvidar entonces que el juez, antes de adjudicar la respuesta, tiene que sopesar y escoger, entre las muchas interpretaciones y argumentaciones que se entrecruzan entre las partes, aquella ratio decidendi que solucione la aporía legal, es decir, aquella solución lógica que tenga el argumento más fuerte y que motive persuasivamente la decisión judicial que se va aplicar al supuesto fáctico concreto. De lo contrario, será un argumento débil y un dicho de paso del juez obiter dictum que no resuelve el conflicto interpretativo planteado en el supuesto fáctico concreto. 
Sin embargo, para Hart (1961), cuando el juez se enfrente a un caso difícil, es discrecional al elegir la respuesta más razonable que va adjudicar al supuesto fáctico concreto según sus preferencias políticas. De hecho, para Hart, cuando el sistema de reglas es de textura abierta y de contextura indefinida y por tanto la ley no ofrece una respuesta determinada al supuesto fáctico concreto, esa es la oportunidad que tiene el juez Herbert para crear una regla nueva de decisión judicial ad hoc de manera discrecional, pues la sentencia será en este caso lo que el juez quiere que ella sea y no lo que la ley dice, siempre claro está que esa elección sea imparcial y se acepte socialmente como el producto razonado y suficientemente informado.

Finalmente, en este debate se encuentra Duncan Kennedy (1999), quien sostiene que aunque el juez tiene libertad para crear reglas hermenéuticas, también tiene restricciones internas y externas en el momento de la proferir la decisión judicial. El sentido de la decisión depende de las primeras impresiones que se forme el juez del caso, de los prejuicios, de las emociones, de las pasiones, de la concepción filosófica y política, de la concepción económica y social, es decir, de las circunstancias jurídicas y metajurídicas de experiencia que tenga el juez, la presión psicológica del tiempo y de las pruebas.

En conclusión, el juez debe ser técnico y apolítico; algunas veces, el juez debe actuar estrictamente mediante el uso del silogismo cuando se encuentra frente a un caso fácil que se adecúe a una norma clara y que resuelve correctamente el problema planteado, caso en el cual la premisa mayor está conformada por las normas generales, la premisa menor lo está por los supuestos fácticos concretos, y finalmente en la conclusión se adjudicarán los derechos y deberes a cada parte, pues según H.L.A. Hart (1961, p. 176) los derechos y deberes humanos son lo que dicen los tribunales que son en sus sentencias. Es más, a mi juicio y siguiendo a Duncan Kennedy, el caso será fácil o difícil dependiendo de la experiencia concreta que tenga el juez en el manejo interpretativo de las normas, la jurisprudencia, los principios, las reglas y la valoración del acervo probatorio al resolver el supuesto fáctico concreto y no tanto de si la norma ofrece respuesta única o admite varias respuestas, pues cuando el caso es difícil, a mi juicio, el juez debe ampliar el periodo de las pruebas ("instrucción suplementaria”) para llegar a la certeza moral.

\section{TÉCNICA DE HERMENEÚTICA CONSTITUCIONAL: EL TEST DE} IGUALDAD Y LA INTERSECCIÓN ENTRE DERECHOS Y LIBERTADES

Ciertamente, el ideal en la interpretación constitucional es garantizar la eficacia divergente de las normas constitucionales que consagran derechos y libertades diferentes, pero el operador jurídico también se puede encontrar en ciertos casos en los que no es posible garantizar la eficacia bipolar, y por ende, se hace necesario jerarquizar y ponderar qué derecho prevalece con respecto a otro, evento en el cual se emplea la técnica del balancing test. En efecto, y según la jurisprudencia de la Corte Constitucional en la Sentencia C-022 de 96, el juicio fuerte nos ayuda a establecer si hay violación de la igualdad a través del test de razonabilidad, es decir, porque no se aducen razones objetivas para justificar un trato diferente y, por tanto, se está discriminando a las personas, pues cuando existen razones objetivas para justificar un trato diferente, no hay discriminación a la igualdad. Por ello, se puede tratar igual a los iguales y desigual a los desiguales sin que se desconozca el artículo 13 de la Carta Magna, en cuyo caso estaríamos en presencia de un juicio débil. De suerte que la acción afirmativa que busca restablecer la igualdad formal y material de los grupos que 
se encuentran en desventaja frente a la ley, será válida siempre que no haya discriminación inversa o siempre que no haya un trato justificador y razonable que permita tratar igual a los iguales y desigual a los desiguales.

\section{EL PRECEDENTE Y EL VALOR VINCULANTE}

¿Puede una sentencia que produce efectos jurídicos interpartes ser considerada como precedente? Personalmente, tengo mis dudas razonables. En conclusión: ¿cuándo una sentencia constituye precedente? Primero, cuando produce efectos erga omnes según el artículo 243 de la Constitución Política de 1991 y el artículo 48 inciso 1 de la Ley 270 de 1996, y no produce efectos interpartes, cuando es proferida por una Corte de cierre, cuando una sentencia se fundamenta en medios de pruebas y cuando no ha sido declarada nula, pues lo cierto es que el artículo 49 inciso 2 del Decreto 2067 de 1991 permite la nulidad de las sentencias de la Corte Constitu-cional por violación del debido proceso.

Según la jurisprudencia de la Corte Constitucional, no se puede confundir la cosa juzgada material con la cosa juzgada formal; la cosa juzgada material se presenta "cuando una norma que fue declarada exequible por la Corte Constitucional es reproducida nuevamente en un proyecto de ley que se somete al control de constitucionalidad" (Sentencia C-090 de 2014). Los salvamentos de voto no constituyen precedente, y únicamente se puede cambiar el precedente constitucional cuando la ciencia aporta suficientes evidencias científicas y elementos de juicio que son razonables y persuasivos que obligan a cambiar la línea jurisprudencial, pues el desconocimiento del precedente puede constituir el delito de prevaricato según lo determinó la Sentencia C-355 de 2008 de la Corte Constitucional. Así, por ejemplo, en la sentencia SU-047 de 99 se estableció:
El respeto a los precedentes cumple funciones esenciales en los ordenamientos jurídicos, incluso en los sistemas de derecho legislado como el colombiano. Para comprender el alcance de la obligatoriedad de un precedente: "stare decisis", resulta indispensable distinguir entre los diversos aspectos de una decisión judicial: "ratio decidendi" —razón de la decisión que adquiere el valor de precedente vinculante y es criterio obligatorio para los otros jueces en casos similares-, los "obiter dictum" — dichos de paso—y el "decisum" que es la resolución concreta del caso.

\section{CONFLiCTO ENTRE UN TRATADO INTERNACIONAL Y la Constitución Política}

Con respecto a la Sentencia C-400 de 1998, es claro que la Corte Constitucional de Colombia debió declararse inhibida para conocer sobre la demanda de inconstitucionalidad de la Ley 406 de 1997, aprobatoria de la Convención de Viena sobre el Derecho de los Tratados en virtud del principio de legalidad, porque el juez constitucional no tiene la competencia sobre tratados ya perfeccionados según la regla de reconocimiento preexistente al acto que se imputa, pues la Corte Constitucional solamente tiene competencia y jurisdicción con respecto a los tratados internacionales que se celebren a partir de la entrada en vigencia de la Constitución Política de 1991.

Ahora bien, si llegare a existir un conflicto normativo entre un tratado internacional celebrado con anterioridad a la entrada en vigencia de la Constitución Política de 1991 y una norma actual de la Constitución, es claro que prevalece la norma internacional en virtud de los principios conocidos como: "pacta sunt servada y principio de Estoppel” (artículos 26 y 45, Convención de Viena sobre el Derecho de los Tratados, 1969). Esto se debe a que las 
reservas de incompatibilidad deben hacerse en el momento oportuno, es decir, antes del momento de la rúbrica y el canje de instrumentos públicos según lo establece la Convención de Viena sobre el Derecho de los Tratados; es más, la Corte Constitucional colombiana únicamente puede hacer control de constitucionalidad de tratados que se celebren después de 1991 como en el caso del TLC con Estados Unidos.

El nuevo trámite para celebrar tratados internacionales exige: según el artículo 189 inciso 2 de la Constitución Política de 1991, le corresponde al presidente la selección del equipo negociador del tratado para acordar las cláusulas del convenio (convención; ONU, 1961, artículo 3, literal a y c) y según los poderes plenipotenciarios acreditados ante el Estado receptor (ONU, 1969, artículos 6 y 7, literal a). Debate y aprobación por mayoría absoluta en el Congreso de la República (artículos 101 y 150, inciso 16). Revisión constitucional (control automático e integral) y previo de la ley aprobatoria (artículo 241, numeral 10, Constitución Política). Posteriormente, se procede a realizar las reservas internacionales con respecto de las normas de la convención que fueron declaradas inexequibles en virtud de la sentencia de la Corte Constitucional de Colombia, según los artículos 22 y 23 de la Convención de Viena sobre la Celebración de Tratados Internacionales, y finalmente se procede a la firma y canje de instrumentos públicos según las normas internacionales (artículos 11, 12, 13, 14, 15, 16, 17, 24, 26 y 27 de la Convención de Viena sobre el Derecho de los Tratados, 1969), momento en cual entrará en vigencia el tratado internacional, y después de surtido este trámite ya no se puede alegar por estado el incumplimiento del tratado por desconocimiento de una norma interna en virtud del principio pacta sunt servada.

La pregunta es si aceptamos en gracia de discusión que algunas de sus cláusulas del
Concordato fueron declaradas inconstitucionales por la Sentencia C-027 de 1993 de la Corte Constitucional de Colombia, entonces, con fundamento en ese precedente, los tratados limítrofes que definieron fronteras con las hermanas repúblicas podrían ser sometidos a revisión constitucional. En mi opinión personal, la Corte Constitucional de Colombia debió declararse inhibida porque no tiene competencia para avocar la exequibilidad de tratados internacionales anteriores a 1991 por el principio de legalidad, que establece que el juez juzga con base en la ley prexistente al acto que se imputa. No obstante, la Iglesia católica, por protocolo internacional, es la decana del Cuerpo Diplomático y preserva la condición permanente de neutralidad y observadora de Naciones Unidas, por ende, respeta las decisiones de las Cortes de Justicia de los Estados con principios radicales y aconfesionales, aunque no comparte su ratio decidenci, pues las otras religiones podrían simplemente exceptuar aquellas normas del concordato que son incompatibles con sus propias leyes, como lo permite el artículo 4 de la Regla de Reconocimiento.

Por ejemplo, la Corte Constitucional de Colombia en la Sentencia C-1022-1999, que define límites con Honduras, cometió una violación al debido proceso constitucional al avocar el control de constitucionalidad de un tratado celebrado en San Andrés el día 2 agosto de 1986, pues el control de constitucionalidad de este tratado debió sujetarse a los procedimientos de la Constitución Política de 1886 que sí define de forma clara los límites territoriales en su artículo 3; y no con fundamento en la Constitución Política de 1991 porque no era la ley preexistente al acto que se imputa.

Lo curioso es que el Congreso de la República de 1999 aprobó la Ley 539 el día 13 de diciembre de 1999 cuando la competencia debió ser del Congreso de la República de 1986, según lo establece el artículo 76 numeral 20 
de la Constitución de 1886. Es más, el artículo 120 numeral 10 y el artículo 151 numeral 8 de la Constitución de Núñez y Caro establecían que la Corte Suprema de Justicia de ese entonces debió aprobar dicho tratado y no la Corte Constitucional de 1991. Esto es puesto que no tiene ninguna lógica que la Corte Constitucional de Colombia avoque retroactivamente el control de constitucionalidad de un tratado antiguo, y mucho menos después de trece años de haberse celebrado el tratado el día 2 de agosto de 1986. O ¿será que el Congreso de República de Colombia de 1999 y la Corte Constitucional de Colombia con la declaratoria de exequibilidad de la Sentencia C-1022 de 1999 pretenden subsanar con este control posterior un vicio procedimental que debió ser subsanado antes de 1991? Pues la Constitución Política de 1991 establece que es un control automático y previo para los tratados internacionales que se celebren desde la fecha de la promulgación de la Constitución de 1991 por la Asamblea Nacional Constituyente.

\section{Conclusiones}

Uno de los grandes problemas de la Constitución Política de 1991 es que haya propiciado el llamado "choque de trenes", y esto se manifiesta con una Corte Constitucional de naturaleza política y no de naturaleza jurídica como lo debe ser una Corte Constitucional contemporánea. No obstante, el panorama de la justicia constitucional colombiana se complica cuando algunos de los jueces constitucionales citan en sus fallos, por ejemplo, las sentencias de la Corte Suprema de Estados Unidos o de Cortes de Justicia de Europa que no son fuente obligatoria del orden jurídico colombiano según lo establece claramente la Constitución Política de Colombia. Y aunque las sentencias de las Cortes Supremas de Justicia de los países extranjeros pueden ser fuentes del derecho obligatorias en sus respectivos países donde tienen jurisdicción, lo cierto es que esas sentencias extranjeras no pueden ser fuentes del derecho ni precedentes en Colombia. En resumidas cuentas, no se puede confundir las fuentes del derecho colombiano establecidas en el artículo 230 de la Constitución Política de 1991 y la Ley 153 de 1887 con las fuentes de la decisión judicial o de la argumentación jurídica de tesis constitucionales, pues en este último caso: "las fuentes de la argumentación jurídica se construyen en cada caso" (González, 2006).

Por ejemplo, un juez o un jurista puede utilizar jurisprudencia de la Corte Suprema de Justicia de Estados Unidos para sustentar un caso, pero ello no quiere decir que esa jurisprudencia norteamericana sea una fuente del derecho en Colombia. Ahora bien, ¿qué sucede si en un caso difícil los magistrados que son de un partido político hacen mayoría a la hora decidir y vencen a una minoría que a la luz de la ciencia retórica (probatoria) tiene la respuesta correcta? La respuesta judicial será correcta y válida si tiene argumentos convincentes y pruebas que se practicaron de forma lícita y además constitucional (Diffie y Landau, 2008).

En este sentido, el honorable magistrado Yesid Ramírez Bastidas sostiene:

La prueba ilícita debe ser indefectiblemente excluida y no podrá formar parte de los elementos de convicción que el juez sopese para adoptar la decisión en el asunto sometido a su conocimiento, sí que pueda anteponer su discrecionalidad ni la prevalencia de los intereses sociales. Las pruebas inconstitucionales son aquellas que se obtienen en clara violación de un derecho fundamental como el debido proceso, el derecho de defensa técnica, o se obtienen en clara vía de hecho. (Corte Suprema de Justicia, Sala Casación Penal, 2009, Proceso 32193) 
Este es el debate constitucional que se plantea Alexander Bickel (1986, p. 16), en tanto en cuanto el juez contramayoritario tiene el poder jurídico y en algunos casos puede poner en jaque a la Sala mayoritaria si en el salvamento de voto denuncia los delitos, las irregularidades, los impedimentos, o revela la evidencia forense que no se tuvo en cuenta en el plenario.
Por ende, es nuestra opinión que la justicia constitucional tiene que ser imparcial e independiente de los intereses políticos del partido, y sus decisiones deben ser objetivas y basarse en estándares de pruebas razonables (Páez, 2015).

\section{REFERENCIAS}

Azula Camacho, J. (2004). Manual de derecho procesal. Tomo II. Editorial Temis.

Bickel, A. M. (1986). The Least Dangerous Branch: The Supreme Court at the Bar Politics. Yale University Press.

Congreso de la República de Colombia. (1887, agosto 24). Ley 153 de 1887. Que adiciona y reforma los Códigos nacionales, la Ley 61 de 1886 y la 57 de 1887. Diario Oficial 7151.

Congreso de la República de Colombia. (2012, julio 12). Ley 1564 de 2012. Por medio de la cual se expide el Código General del Proceso y se dictan otras disposiciones. Diario Oficial 48.489.

Corte Constitucional de Colombia. (2016, febrero 24). Sentencia C-086 de 2016 (Jorge Iván Palacio Palacio, M. P.). Diffie, W. y Landau, S. (2008). Brave New World of Wiretapping. Scientific American, 299(3), 56-63.

D’Ors, Á. (Coord.). (1968). El Digesto de Justiniano. Aranzadi.

Dworkin, R. (1978). Taking Rights Seriously. Harvard University press.

González Jácome, J. (2006). El problema de las fuentes del derecho, una perspectiva desde la argumentación jurídica. Revista Universitas, 55(112), 265-293. https://revistas.javeriana.edu.co/index.php/vnijuri/article/ view/14650

Hart, H. L. A. (1961). The Concept of Law. Oxford University Press.

Kennedy, D. (1999). Libertad y restricción en la decisión judicial. Siglo del Hombre Editores.

López Blanco, H. F. (2009). Procedimiento civil. Editorial Dupré.

López Medina, D. E. (2006). El derecho de los jueces. Editorial Legis.

Organización de las Naciones Unidas (ONU). (1961). Convención de Viena sobre Relaciones Diplomáticas. onU. Organización de las Naciones Unidas (ONU). (1969). Convención de Viena sobre la Celebración de Tratados Internacionales. ONU.

Páez, A. (2015). Hechos, evidencia y estándares de prueba: ensayos de epistemología jurídica. Ediciones Uniandes. Quinché Ramírez, M. F. (2017). El control de convencionalidad. Editorial Temis.

Quinché Ramírez, M. F. (2015). Derecho procesal constitucional colombiano. Doctrina y Ley. 


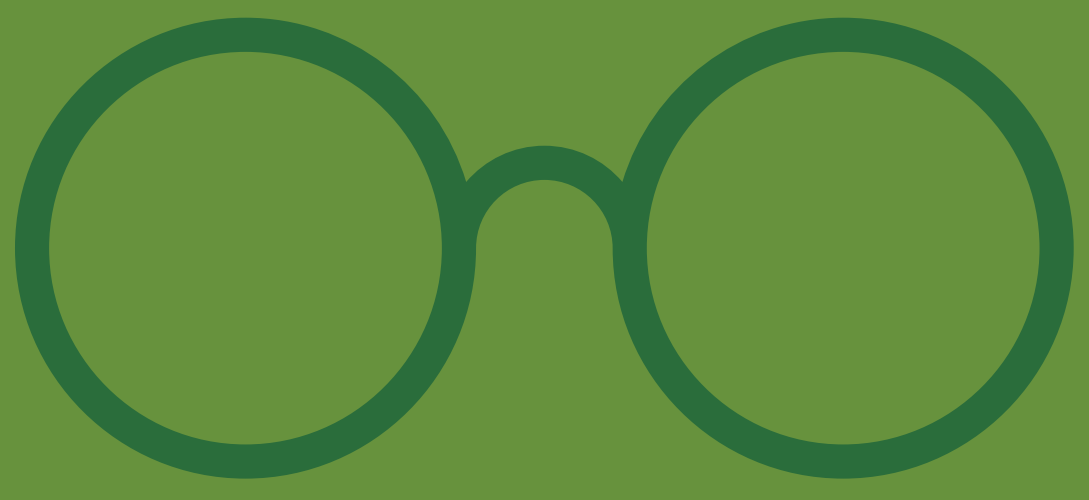

